\title{
Evaluating Public Engagement for a Consensus Development Conference
}

\author{
Michelle Chan, $\mathrm{PhD}^{1}$ and Konrad Fassbender, $\mathrm{MA}, \mathrm{PhD}^{1,2}$
}

\begin{abstract}
Background: Effectively engaging Canadians to help improve the quality and delivery of healthcare to dying Canadians is a priority for healthcare administrators and policy makers. This report shares our evaluation and learnings, applying a series of strategies to encourage policy formation. The Palliative Care Matters consensus development conference held in Ottawa on November 7-9, 2016 brought together members of the public, stakeholders, scientific experts, and a lay panel of interested Canadians to examine Canadian public opinions on palliative care and question experts on how palliative care could be enhanced.

Objective: This report shares our evaluation and learnings applying a series of strategies to encourage policy formation.

Methods: An evaluation was conducted to measure the short, intermediate, and identify long-term outcomes of the conference. The overall performance of the conference for public engagement from November 2016 to mid June 2017 is shared.

Results and Conclusion: The outcome of the conference was positive. It was attended and watched online by over 400 participants, received national print, radio and television coverage, and generated high exposure and engagement on social media. Survey results showed that the majority of steering committee, expert, and lay panel members felt a high level of engagement and agreed that the engagement process was successful. Evaluation will be conducted on an ongoing basis for at least another year.
\end{abstract}

Keywords: consensus development conference; evaluation; palliative care; public engagement

\section{Evaluation Purpose and Scope}

$\mathbf{E}$ FFECTIVELY ENGAGING CANADIANS to help improve the quality and delivery of healthcare to dying Canadians is a priority for healthcare administrators and policy makers. In this report, we share our evaluation and learnings applying a series of strategies to encourage policy formation.

The Covenant Health Palliative Institute, in partnership with Canada's leading healthcare organizations, undertook an initiative, known as Palliative Care Matters (PCM), to examine palliative care needs across the country. The strategies included an IPSOS public poll, a consensus development conference, and a Conference Board report. This conference was organized to develop a national consensus statement and recommendations to promote consistent and timely access to high-quality, coordinated, and integrated palliative care. This initiative and strategies were developed to encourage and enhance public engagement.

The conference brought together members of the public, stakeholders, scientific experts, and a lay panel of interested
Canadians to examine Canadian public opinions on palliative care and question experts on how quality palliative care could be delivered.

In this report, the overall (board-level) performance of the conference for public engagement is shared and discussed. Evaluation of the conference is based on the following measures, all of which will be ongoing for at least another year.

1. At the end of the day, success of the conference depends on the number of Canadians aware of and engaged in PCM. This will be measured through the number of attendees, webcast registrants, video views, media exposure, social media exposure and engagement, and downloads/views of the IPSOS survey news release, consensus statement, and Conference Board of Canada report.

2. To assess the planning, execution, and impact of the conference on members of the public and those more directly involved in the conference, a Public and Patient Engagement Evaluation Tool (PPEET) developed

\footnotetext{
${ }^{1}$ Covenant Health Palliative Institute, Edmonton, AB, Gray Nuns Community Hospital, St. Marguerite Health Services Center, Edmonton, Alberta, Canada.

${ }^{2}$ Department of Oncology, Edmonton, AB, University of Alberta, Edmonton, Alberta, Canada.

Accepted August 22, 2017.
} 
at McMaster was adapted and administered among the public audience, steering committee, scientific experts, and lay panel members.

3. A Reflection Room was created by Saint Elizabeth and installed at the conference. The room was designed to give visitors a quiet space to reflect upon stories on death and dying. Visitors were given the opportunity to write their reflections on a card and pin it to the wall. These cards were scanned, transcribed, and posted to http://thereflectionroom.ca. Content analysis was conducted to identify emerging themes (concepts) from the data.

4. Intermediate measures include the number of downloads/views and of the IPSOS survey news release, consensus statement, Conference Board of Canada report, and academic articles. A citation index will eventually be created based on the amalgamation of these figures.

5. Long-term measures include the number of recommendations and PCM-related activities which have been adopted and undertaken by governments and other stakeholders. Adoption can be measured as a count or as a dollar value, although numbers will likely not be available for at least 1 to 3 years. Longterm success also requires repeating some of the questions on the Ipsos "Canadians' Views of Palliative Care" survey and measuring whether PCM had an impact on Canadian knowledge, attitudes, and actions on palliative care. A workplan and resources would be required to formally assess these long-term measures.

\section{Attendance and Video Views}

The conference was attended by 110 participants -42 were regular registrants, 15 were sponsor representatives, and 3 were volunteers. The remaining attendees were speakers/committee members (30), experts (12), and lay panel members (8).

Two hundred thirty sites registered to watch the live webcast. One hundred ninety-three registrants indicated that they watched on their own, 27 indicated that they watched with 1-3 colleagues, 6 watched with 3-5 colleagues, 3 watched with 5-10 colleagues, and 1 watched with more than 10 colleagues. Taking into account those that watched as a group, the estimated total number of viewers was 339 (1-3 colleagues were counted as 2 viewers, 3-5 colleagues were counted as 4 viewers, 5-10 colleagues were counted as 7 viewers, and more than 10 colleagues were counted as 10 viewers). Registrants watched from across Canada, the United States, the United Kingdom, the Netherlands, Switzerland, Italy, Indonesia, Kenya, Nigeria, Mexico, Saudi Arabia, and Tanzania.

The webcast generated a total of 1,069 live views and 546 archived views, for a total of 1,615 views.

\section{Media}

A systematic media search was conducted to identify relevant articles on PCM printed after November 1, 2016. The following databases were used: Eureka.cc, Canadian Newsstream, Canadian Periodicals Index (CPI.Q), Factiva, PressReader, and Google News. The search covered daily major
Canadian newspapers (e.g., Calgary Herald, Edmonton Journal, Globe and Mail, Montreal Gazette, National Post, Ottawa Citizen, Toronto Star, Vancouver Sun, Victoria Times Colonist), as well as smaller newspapers (e.g., Truro Daily News and The Telegram).

Radio and television coverage was conducted by searching through the online archives of the following major Canadian radio and television broadcasts: CBC Radio, CBC TV, CTV News, and Global TV.

The search for all media coverage was conducted on a monthly basis between November 2016 and June 2017 and included English and French language media.

The following search terms were used: (1) "palliative care matters," (2) "palliative care" AND "conference," (3) "consensus development conference," (4) "palliative care", AND “consensus development conference," (5) "palliative care" AND "Karen Macmillan," (6) "palliative care" AND "Fred Horne," (7) "palliative care" AND "Covenant Health," (8) "l'importance des soins palliatifs," (9) "soins palliatifs" AND "conference," (10) "conférence de consensus," (11) "soins palliatifs" AND "conférence de consensus," (12) "soins palliatifs" AND "Karen Macmillan," (13) "soins palliatifs" AND "Fred Horne," and (14) "soins palliatifs" AND "Covenant Health."

\section{Results}

The search yielded 5 press releases, 8 news articles on the conference, $19 \mathrm{CBC}$ radio broadcasts, and 2 television broadcasts. PCM was also cited in 3 parliamentary briefings. See Appendix 1 for a full list of the media coverage.

\section{Social Media}

The PCM initiative used Facebook (@palliativecarematters) and Twitter (@PalliativeCM) to promote the conference, share news and updates, and feature links, videos, and photos related to PCM. To evaluate the success of social media on public engagement, a metric called "engagement rate" was calculated. Engagement rate measures the level of interaction (likes, shares, retweets, comments, clicks, etc.) among users who saw a social media post. Engagement rate is the most important metric in social media and can be used to measure the success of a fan page on public engagement. ${ }^{1}$

Other metrics such as "reach" can provide information about the number of people who saw any post content on the PCM Facebook page or Twitter account. "Mentions" can show how often people talk about PCM, as reflected by the number of times people mention PCM or put @ palliativecarematters (Facebook) @ PalliativeCM (Twitter) in their posts and tweets. ${ }^{2}$

In Facebook, engagement rate is calculated as ${ }^{3,4}$ :

Total number of users that liked, clicked, shared,

$$
\frac{\text { or commented on a post }}{\text { Total number of users who saw the post (Reach) }} \times 100
$$

To measure engagement rate, reach, and mentions of the PCM Facebook page, analytics data between July 21, 2016 and June 20, 2017 were used ( $N=43$ posts). These data were available through Facebook Insights, a dashboard that allows one to track user activity on a fan page. The overall 
engagement rate was calculated by taking the average engagement rate for the 43 posts made by the PCM Facebook page. A 2016 Benchmark Study conducted by $\mathrm{M}+\mathrm{R}$ analyzed Facebook data from 105 nonprofit organizations for the entire year of 2015. The study found that the average Facebook engagement rate for a nonprofit Facebook post is $5.4 \% .^{5}$

In Twitter, engagement rate is calculated as ${ }^{6}$ :

Total number of users that interacted with a Tweet $\frac{\text { Total number of time the Tweet was seen (Impressions) }}{\text { Tim }} 100$

Interactions include retweets, replies, follows, likes, links, and clicks anywhere on the Tweet. ${ }^{6}$

To measure engagement rate, reach, and mentions of the PCM Twitter account, analytics data between July 21, 2016 and June 20, 2017 were used ( $n=231$ tweets). These data were available through Tweetchup and Twitter Analytics, two dashboards that track user activity on Twitter. The overall engagement rate was calculated by taking the average engagement rate for the 231 tweets made by the PCM Twitter account. A 2016 Benchmark Study conducted by M\&R analyzed Twitter data from 105 nonprofit organizations for the entire year of 2015. The study found that the average Twitter engagement rate for a nonprofit tweet is $1.6 \% .^{5}$

Aside from tracking the number of times people put @ palliativecarematters (Facebook) or @ PalliativeCM (Twitter) in their posts, the following search terms were used on Facebook and Twitter: (1) \#palliativecarematters, (2) "palliativecarematters," (3) "palliative care matters," (4) "palliative care" AND "conference," (5) "consensus development conference," (6) "palliative care" AND "consensus development conference," (7) "palliative care" AND "Karen Macmillan," (8) "palliative care" AND "Fred Horne," (9) "palliative care" AND "Covenant Health," (10)"l'importance des soins palliatifs," (11) "soins palliatifs" AND "conference," (12) "conférence de consensus," (13) "soins palliatifs" AND "conférence de consensus," (14) "soins palliatifs" AND "Karen Macmillan," (15) "soins palliatifs" AND "Fred Horne," and (16) "soins palliatifs" AND "Covenant Health."

\section{Results}

The PCM Facebook page reached a total of 10,212 people, whereas the Twitter account potentially reached 105,079 people. There were 261 mentions of PCM on Twitter and 50 mentions on Facebook. Engagement rate on Facebook was $12 \%, 2.2$ times higher than the average engagement rate for a nonprofit organization Facebook page (5.4\%). Engagement rate on Twitter was $1.3 \%$, similar to the average engagement rate for a nonprofit organization Twitter account (1.6\%). While these findings show that social media were effective in reaching and engaging an online audience, the relationship between engagement and mid- to long-term outcomes is unknown.

\section{Evaluation Surveys}

To evaluate the public engagement process of the consensus development conference, an electronic postconference survey was developed for each of the following five audiences: live audience, online audience, stakeholders, scientific experts, and lay panel members.
The design was a cross-sectional, self-administered, anonymous questionnaire survey. The survey instruments were developed in collaboration with BUKSA Strategic Conference Services and Canadian Foundation for Healthcare Improvement (CFHI). Development of the live audience, online audience, and stakeholder surveys was adapted from the Public and Patient Engagement Evaluation Tool (PPEET) published by McMaster University. The tool is built around the five core principles of the IAP2 spectrum (International Association for Public Participation): Inform, Consult, Involve, Collaborate, and Empower. The purpose of developing PPEET was to have a common evaluation tool that can be used across a wide range of initiatives/organizations to create a robust base of evidence about public engagement effectiveness and to inform future practice. ${ }^{7}$

The surveys were programmed in SurveyMonkey and emailed to attendees after the conference was completed. The surveys were sent to the live and online audience on November 15, 2016 and sent to the steering committee, experts, and lay panel on November 17, 2016. Attendees were given until December 14, 2016 to respond. To ensure a high response rate, each survey was designed to have few questions that were simple and easy to understand. The draft questionnaire for each audience was reviewed within the evaluation planning group to reduce the length and complexity of the survey. Questions from PPEET were modified to be consistent with the consensus development conference concept. The questionnaire was also amended to include additional questions on conference logistics/organization. Based on a pretest of the questionnaires, it was estimated that respondents would be able to complete each survey within 5 minutes.

The final survey questionnaire for the live and online audience consisted of queries about conference content and conduct, conference logistics, and overall satisfaction with the conference. The questionnaire also consisted of openended questions on what was the best thing about the conference and what could have been done differently to improve the conference. The online audience survey consisted of additional queries about webcast logistics.

The final survey questionnaire for the expert and lay panel consisted of queries about their participation on the panel, conference content and conduct, conference logistics, and overall satisfaction with the conference. The questionnaire also consisted of open-ended questions to evaluate the impact of the consensus statement, challenges/obstacles the respondents faced, what respondents appreciated most about the conference, personal benefits gained from participating in the conference, and what could have been done differently to improve the conference.

The final survey questionnaire for the steering committee was similar to the expert/lay panel questionnaire, but consisted of additional queries about the integrity of design and process of the conference, influence and impact of the conference, and collaboration and common purpose with other stakeholders.

Response rates achieved for the surveys are as follows: inperson participants $(25.0 \%)$, online participants $(11.7 \%)$, steering committee $(43.8 \%)$, expert panel $(87.5 \%)$, and lay panel $(83.0 \%)$.

Due to technical error, we received lower than average response rates for the in-person and online participants. Thus, 
we directed our efforts to focusing on the steering committee, expert, and lay panel surveys.

\section{Results}

The results showed that the majority of steering committee, expert, and lay panel respondents agreed that the engagement process was successful. This was demonstrated through statements of agreement of the following PPEET questions: (a) 100\% of respondents "agreed" or "strongly agreed" that they could express their views freely at the conference and that those views were heard, (b) $100 \%$ of respondents "agreed" or "strongly agreed" that the consensus statement would make a difference in palliative care in Canada, (c) the majority of steering committee members $(86 \%)$ indicated that the consensus statement would be shared within their organizations, and (d) $100 \%$ of respondents "agreed" or "strongly agreed" that they were satisfied with the conference overall.

\section{Reflection Room}

Twelve visitors wrote a story in the Reflection Room that was installed at the conference. Their stories can be read at $\mathrm{http}: / /$ thereflectionroom.ca/tag/ottawa-pcm. The stories were transcribed and thematically coded by the Saint Elizabeth Research Team.

\section{Results}

The frequency distribution of concepts coded for the 12 stories are: memories $(6 / 12)$, perspective $(6 / 12)$, reflection $(6 /$ $12)$, gratitude (4/12), moments (4/12), relationships (4/12), grief (3/12), experiences (3/12), learning (2/12), and regret $(1 / 12)$.

\section{Views and Downloads}

\section{Ipsos survey news release}

On September 21, 2017, PCM released the results of the Ipsos "Canadians' Views of Palliative Care" survey. Between September 21, 2017 and June 13, 2017, the press release received 9,181 page views on the Ipsos website (www. ipsos-na.com/news-polls/pressrelease. $\operatorname{aspx}$ ?id=7379). As per their privacy policy, user demographics and number of downloads of the full survey report (from subscribers) could not be shared by Ipsos.

\section{Website and consensus statement}

Analytics data of the PCM website (www.palliativ ecarematters.ca) were collected through Google Analytics between September 23, 2016 and June 13, 2017. There were a total of 9,308 visits to the website and 22,191 page views during that period. The consensus statement received 204 page views since it was published on November 25, 2017.

\section{Conference board of Canada report}

The Conference Board of Canada released its report on the PCM initiative on May 10, 2017. The report, called Palliative Care Matters: Fostering Change in Canadian Health (available at www.conferenceboard.ca/e-library/abstract. aspx?did=8807), outlines key themes from the initiative, recommendations that may be taken to improve palliative care and potential next steps.

As provided by the Conference Board, the PCM report was downloaded 135 times from the Conference Board e-library between May 10, 2017 and June 13, 2017. A breakdown of the top industries that downloaded the report is as follows: universities $(19 \%)$, physicians $(11 \%)$, provincial government (10\%), hospitals (8), federal health administration (5\%), provincial health administration (4\%), nursing care facility (4\%), outpatient facility (4\%), and consulting services $(3 \%)$.

A webinar about the report was copresented by Carole Stonebridge (Conference Board) and Konrad Fassbender (Scientific Director, Palliative Institute, Covenant Health) on May 31, 2017. The webinar was attended by 40 individuals/ organizations, comprising of researchers, governments, healthcare organizations, and other stakeholders.

\section{Limitations and Lessons Learned}

Public engagement science is rapidly evolving. Engagement of the public becomes more effective along the following spectrum: inform, consult, involve, collaborate, and empower. Assessing the degree of effectiveness, however, is more challenging. This report includes observable participation through conventional measures such as attendance, readership, and viewership. Various measures of activity in social media have likewise been captured by this report. Altogether, these analytics do not predict how many or which individuals will act in a meaningful manner. Effective active participation in a democratic country is likewise variable and indeterminate. Should public members, for example, be encouraged to write to their MPs and MLAs? There is a gap in our understanding on how best to measure the degree and exact nature of the intended participation, although the evaluation surveys did include the concepts, such as optimism.

A number of specific learnings could be summarized as follows:

- The conference was scheduled during the U.S. election, which curtailed our ability to effectively promote media uptake of the conference itself.

- Data are presented utilizing current industry reporting standards, which often estimate the number of people reached. We are aware that various methods of identifying engagement rates may overestimate the unique number of people reached. This type of media reporting is one method of recording access to information, which constitutes first level of engagement.

- Web analytics software should have been implemented at an earlier stage to capture more metrics of the consensus statement, such as number of downloads and users' geographic locations.

- As we did not foresee that many radio broadcasts would not be archived online, we should have kept better track of the interviews conducted on radio (e.g., radio station, title of interview).

- Reach numbers of each print and broadcast media outlet were not publicly available, thus we were unable to track the number of people reading, watching, or listening to PCM-related media. 
- Finally, as per the privacy policy of Ipsos and the Conference Board of Canada that covers what information is collected and disclosed, we were unable to obtain certain usage data of the Ipsos survey and Conference Board reports, such as number of subscriber downloads (of the Ipsos report) and demographics of users.

Leveraging the media effectively requires investment into the development of media plans and hiring PR firms with extensive networks and connections. Our lay panel chair was a media personality and allowed us to leverage his networks. Each of the partner organizations have media advisors, who could have been used more effectively if asked to participate in a separate subcommittee.

\section{Conclusions}

Table 1 summarizes the number of people aware of PCM and the amount of media coverage PCM received between November 2016 and mid June 2017.

In total, there were 110 attendees at the consensus development conference, comprising of members of the public, researchers, governments, healthcare organizations, and other stakeholders. Approximately 339 individuals watched the conference webcast from numerous different countries, including Canada, the United States, the United Kingdom, the Netherlands, Switzerland, Italy, Indonesia, Kenya, Nigeria, Mexico, Saudi Arabia, and Tanzania.

The conference generated considerable activity on social media. Facebook reached a total of 10,212 people, whereas the PCM Twitter account reached 105,079 people. An engagement rate was calculated to measure the level of interaction from individuals who saw the social media content (through likes, comments, shares, replies, retweets, etc.). Engagement rate on Facebook was 12\%-2.2 times higher than the average engagement rate for a nonprofit organization

\section{Table 1. Number of People Aware of Palliative} Care Matters and Media Mentions (November 2016 to Mid-June 2017)

\begin{tabular}{lr}
\hline Number of media mentions & \\
Press releases & 5 \\
News articles & 8 \\
Radio broadcasts & 19 \\
TV broadcasts & 2 \\
Parliamentary briefings & 3 \\
Total & 37 \\
Number of people reached & \\
Attendance & \\
In-person & 110 \\
Webcast & 339 \\
Webcast views (live and archived) & 1,615 \\
Social media & 10,212 \\
Facebook reach & 104,691 \\
Twitter reach & \\
Downloads/views & 9,181 (views) \\
Ipsos survey news release & 204 (views) \\
Consensus statement & 135 (downloads) \\
Conference Board of Canada report & 126,487 \\
Total &
\end{tabular}

Facebook page. Engagement rate on Twitter was 1.3\%similar to the average engagement rate for a nonprofit organization. While these findings show that social media were effective in reaching and engaging an online audience, the relationship between engagement and mid- to long-term outcomes is unknown.

Media coverage of the conference comprised 5 press releases, 8 news articles on the conference, $19 \mathrm{CBC}$ radio broadcasts, and 2 television broadcasts.

A Reflection Room at the conference provided the opportunities for attendees to post their personal stories. Content analysis of the 12 stories recorded identified the following themes (concepts) in the stories: memories, perspective, reflection, gratitude, moments, relationships, grief, experiences, learning, and regret.

Survey results from the steering committee, expert panel, and lay panel were positive. The majority of respondents were satisfied with all aspects of the conference, including the engagement process. Respondents felt that the conference increased their knowledge of palliative care issues and appreciated the opportunity to develop networks with other colleagues. One hundred percent of respondents from the steering committee, $86 \%$ of the expert panel, and $100 \%$ of the lay panel stated that the consensus statement will make a difference in palliative care in Canada. Eighty six percent of respondents from the steering committee indicated that they will share and use the consensus statement within their organizations. Several organizations have since disseminated information about PCM through their websites, newsletters, and social media channels, and have referenced PCM and the consensus statement in presentations, parliamentary briefings, and other reports.

To date, the consensus statement on the PCM website has generated 204 page views, whereas the Ipsos survey news release has generated 9,181 number of page views. The PCM Conference Board of Canada report was uniquely downloaded 135 number of times since it was released on May 10, 2017.

This report suggests that the outcome of the PCM conference was positive. It was attended and watched online by over 400 participants, received national print, radio and television coverage, and generated high exposure and engagement on social media. The majority of members from the steering committee, expert, and lay panel were engaged, agreed that the engagement process was successful, and were optimistic about the future impact of the consensus statement in Canada.

\section{Acknowledgments}

The authors thank Carleen Brenneis, Jewel Buksa, Judy Wry, Lisa Cruthers, Katrina Tarnawsky, Maria Judd, and Anya Humphrey for their assistance in developing and piloting the evaluation surveys; Saint Elizabeth Healthcare for bringing the Reflection Room to the conference; Erin Rouston and Jessica Kandaru from Ipsos Canada Public Affairs for providing the number of views of the Ipsos survey news release; Carole Stonebridge and Yvonne Squires from the Conference Board of Canada for providing statistics on the number of downloads of the Palliative Care Matters Conference Board report; and Covenant Health and the Canadian Foundation of Healthcare Improvement for their considerable contributions to funding this research. 


\section{Author Disclosure Statement}

No competing financial interests exist.

\section{References}

1. Niciporuc T: Comparative analysis of the engagement rate on Facebook and Google Plus social networks. In: Proceedings of the International Academic Conferences (No. 0902287). Prague, Czech Republic: International Institute of Social and Economic Sciences, 2014, pp. 334-339.

2. Shively K: 40 Key Social Media Metrics Defined, https:// simplymeasured.com/blog/40-key-social-media-metricsdefined/\#sm.00000uqs52ffedqjts41anzzcwpy3 (Last accessed November 25, 2016).

3. Smith N: Facebook engagement rate, https://simplymeasured. com/blog/facebook-metrics-defined-engagement-rate/\#sm. 00000uqs52ffedqjts41 anzzcwpy3 (Last accessed December 1, 2017).

4. Facebook Help Center. Insights, www.facebook.com/help/ 794890670645072/?helpref=hc_fnav (Last accessed June 12, 2017)
5. $M+R$ Benchmarks: $M+R$ Benchmarks 2016. http://mrbench marks.com/download.php?report=2016 (Last accessed December 1, 2016).

6. Twitter Help Center: Tweet activity dashboard, https:// support.twitter.com/articles/20171990\# (Last accessed June 12, 2017).

7. Abelson J, Li K, Wilson G, et al.: Supporting quality public and patient engagement in health system organizations: Development and usability testing of the Public and Patient Engagement Evaluation Tool. Health Expect 2015;19:817-827.

Address correspondence to: Michelle Chan, PhD Covenant Health Palliative Institute, Edmonton, Alberta Grey Nuns Community Hospital St. Marguerite Health Services Centre 1090 Youville Drive West, Room DC-408-4 Edmonton, Alberta T6 L OA3 Canada

E-mail: mc3@ualberta.ca

\section{APPENDIX 1}

\section{Press Releases}

Canada NewsWire. Steps to improve access to high quality palliative care identified, www.newswire.ca/news-releases/stepsto-improve-access-to-high-quality-palliative-care-identified621853443.html (2017, May 10).

Canada NewsWire. Étapes à suivre pour améliorer l'accès à des soins palliatifs de qualité, www.newswire.ca/newsreleases/etapes-a-suivre-pour-ameliorer-lacces-a-des-soinspalliatifs-de-qualite-621853243.html (2017, May 10).

Canada NewsWire. Statement-Canadian Foundation for Healthcare Improvement supports integrated palliative care, www.newswire.ca/news-releases/statement-canadianfoundation-for-healthcare-improvement-supports-integratedpalliative-care-600863341.html (2016, November 11).

Canada NewsWire. Media Advisory-National Palliative Care Matters Conference puts Canadians at the Center of the Palliative Care Conversation, www.newswire.ca/newsreleases/media-advisory-national-palliative-care-matters-con ference-puts-canadians-at-the-centre-of-the-palliative-careconversation-599637211.html (2016, November 7).

Canada NewsWire. Canadians call for Palliative Care to be enshrined in Health Act, www.newswire.ca/newsreleases/canadians-call-for-palliative-care-to-be-enshrined-inhealth-act-600556991.html (2016, November 9).

\section{News Articles}

Swan, M. Recent polls point to Canadians demanding better palliative care. The Catholic Register, www.catholic register.org/features/featureseries/item/23685-recent-polls- point-to-canadians-demanding-better-palliative-care (2016, November 26).

Local hospice worker helps form ideas to present to federal government. Truro Daily News, www.pressreader.com/ @ Michelle_Chan.2/OP40TQ1NS4P6 (2016, November 21). Library authentication is required to access the link.

Les Canadiens et les Canadiennes demandent que les soins palliatifs soient inscrits dans la Loi sur la santé. ehospice, www.ehospice.com/canadafrench/ArticleView/tabid/10676/ ArticleId/21035/language/fr-FR/Default.aspx (2016, November 17).

Davis, A. Canada will heighten its healthcare service, adds palliative care. Science World Report, www.scienceworld report.com/articles/52011/20161110/canada-will-heightenhealth-care-service-adding-palliative.htm (2016, November 10).

Horne, F. Palliative care is the orphan of the Canadian health system. The Hill Times, www.hilltimes.com/2016/11/ 09/palliative-care-orphan-canadian-health-system/87155 (2016, November 9).

Des intervenants veulent une stratégie nationale en soins palliatifs. MagZ Quebec, http://magzquebec.com/desintervenants-veulent-une-strategie-nationale-en-soins-palliatifs (2016, November 7).

Olivier, P.F. Conférence sur l'importance des soins palliatifs. Journal Métro de Montréal, http://journalmetro.com/ actualites/national/1046956/conference-sur-limportance-dessoins-palliatifs (2016, November 7).

Soins palliatifs: des intervenants veulent établir une stratégie nationale. La Presse, www.lapresse.ca/actualites/sante/ 201611/07/01-5038695-soins-palliatifs-des-intervenants- 
veulent-etablir-une-strategie-nationale-.php (2016, November 7).

\section{Radio Broadcasts}

$18 \mathrm{CBC}$ radio stations interviewed Karen Macmillan and Fred Horne on November 7, 2016, however only two recordings were archived.

Horne, F. Palliative panel. Ottawa Morning. Ottawa: CBC Radio. www.cbc.ca/news/canada/ottawa/programs/ottawa morning/pallative-panel-1.3839612 (2016, November 7).

Horne, F. Fred Horne - Palliative care. Information MorningFredericton with Terry Seguin. Fredericton: CBC Radio, www. cbc.ca/listen/shows/information-morning-fredericton/segment/ 10719190 (2016, November 7).

Savoie, G. \& Downar, J. Soins palliatifs au Canada: portrait des enjeux. Y a pas deux matins pareils. Toronto: CBC Radio. http://ici.radio-canada.ca/nouvelle/813264/soins-palliatifsconference-ottawa-enjeux (2016, November 7).

\section{Television Broadcasts}

Cable Public Affairs Channel (CPAC). Public RecordFrom Consensus to Action: The Palliative Care Matters
Initiative, www.cpac.ca/en/programs/public-record/episodes/ 49747911/(November 9, 2016).

Horne, F. Interview with Julie Ierton. Ottawa: CBC TV. (2016, November 4).

\section{Parliamentary Briefings}

Canadian Hospice Palliative Care Association. The time for action is now: Bill C-277. Brief to the House of Commons Standing Committee on Health (HESA), www.ourcommons. ca/Content/Committee/421/HESA/Brief/BR8816112/brexternal/CanadianHospicePalliativeCareAssociationCHPCAe.pdf (2017, March 9).

Canadian Society of Palliative Care Physicians. Brief to the standing committee on health, Re: Draft bill. www.cspcp. ca/wp-content/uploads/2017/03/C-277-brief-from-PalliativeCare-Physicians-EN-1.pdf (2017, March 2).

Canadian Nurses Association. Bill C-277, an act providing for the development of a framework on palliative care in Canada. Briefing for the Standing Committee on Health, https://cna-aiic.ca/ /media/cna/page-content/pdf-en/bill-c277_submission-to-standing-committee-on-health_march2017. pdf?la=en (2017, March). 